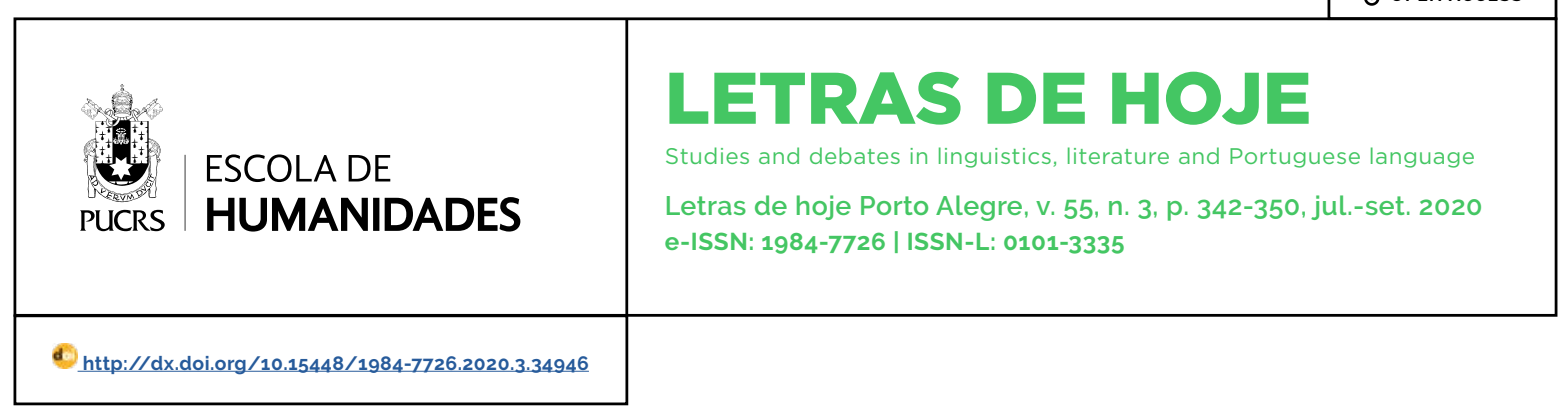

TEMÁTICA LIVRE

\title{
A contação de histórias para crianças autistas
}

\author{
Storytelling for Autistic Children \\ Cuentacuentos para niños autistas
}

\section{Viviane Cristina de Mattos Battistello ${ }^{1}$ orcid.org/0000-0002-0482-8927 vivimattos@feevale.br}

\section{Ana Teresinha Elicker ${ }^{1}$ orcid.org/0000-0003-1432-6506 anaelicker@feevale.br}

\section{Lovani Volmer ${ }^{1}$ \\ orcid.org/0000-0002-3458-1005 lovaniv@feevale.br}

\section{Rosemari Lorenz}

\section{Martins ${ }^{1}$}

orcid.org/0000-0003-0658-5508 rosel@feevale.br

Recebido em: 20/11/2019 Aprovado em: 28/09/2020 Publicado em: $17 / 12 / 2020$

\begin{abstract}
Resumo: O presente artigo visa analisar as contribuições de uma prática de leitura mediada para crianças autistas com nivel leve. A metodologia fundamentou-se nos pressupostos teóricos e no uso de um programa de adaptação de leitura com recurso de apoio visual, visto que é uma alternativa para o desenvolvimento do letramento emergente de crianças com Transtorno do Espectro Autista (TEA). Os resultados mostraram que as práticas de leitura apresentam um papel relevante na socialização de crianças, pois incentivam a interação social, a autonomia e o letramento emergente. As considerações finais reafirmaram os resultados obtidos em pesquisas anteriores, sobre a contribuição da mediação de leitura para o desenvolvimento do letramento emergente de crianças com TEA, principalmente porque a intervenção precoce auxilia no processo de alfabetização. Palavras-chave: Fábulas. Letramento emergente. Mediação da leitura.
\end{abstract}

Abstract: This article aims to analyze the contributions of a mediated reading practice for preschool children with mild level. The methodology was based on the theoretical assumptions and the use of a reading adaptation program with visual support since it is an alternative for the development of the emerging literacy of children with autism spectrum disorder (ASD). The results showed that reading practices have a relevant role in the socialization of children, as it encourages social interaction, autonomy, and emerging literacy. The final considerations reaffirmed the results obtained in previous research on the contribution of reading mediation to the development of the emerging literacy of children with ASD, mainly because early intervention assists in the process of Literacy. Keywords: Fables. Emerging literacy. Reading mediation.

Resumen: Este artículo tiene como objetivo analizar los aportes de una práctica de lectura mediada para niños autistas con nivel leve. La metodología se basó en supuestos teóricos y el uso de un programa de adaptación lectora con apoyo visual, por ser una alternativa para el desarrollo de la alfabetización emergente en niños con Trastorno del Espectro Autista (TEA). Los resultados mostraron que las prácticas de lectura juegan un papel importante en la socialización de los niños, ya que fomenta la interacción social, la autonomía y la alfabetización emergente. Las consideraciones finales reafirmaron los resultados obtenidos en investigaciones anteriores sobre la contribución de la mediación lectora al desarrollo de la alfabetización emergente en niños con TEA, principalmente porque la intervención temprana ayuda en el proceso de alfabetización.

Palabras clave: Fábulas. Alfabetización emergente. Mediación de lectura.

\section{Introdução}

A leitura, mais do que desemaranhar um código, possibilita ao leitor decifrar a si, adentrar em outros mundos- sejam eles do mundo real ou do criado pelas palavras. A priori, é uma temática amplamente discutida na academia, mas, nem por isso, esgotada; há, ainda, muitas veredas a 
serem percorridas e desbravadas, especialmente se levarmos em consideração o letramento emergente e as suas contribuições à aquisição da lectoescrita. Partindo dessa premissa, este estudo pode contribuir no desenvolvimento dessas competências, especialmente se considerarmos crianças com Transtorno do Espectro Autista (TEA).

A leitura de narrativas literárias, cuja característica preponderante é ativar a imaginação, possibilita ao leitor, em qualquer idade, navegar por mares não pessoalmente navegados, viver o não vivido, sentir o não sentido, tornando-o, acima de tudo, mais humano e sensivel frente ao mundo e suas multiplices facetas. As fábulas, nesse sentido, cuja origem está na tradição oral, apresentam-se como possibilidade de trabalho com a Literatura já desde a Educação Infantil, uma vez que a abordagem traz afirmações de fatos imaginários sem intenção deliberada de enganar, mas de promover uma crença na realidade dos acontecimentos, conforme Coelho (2000, p. 165), e a narração tende a ser simples e sucinta.

Nesse sentido, este estudo teve como objetivo analisar as contribuições de uma prática de leitura mediada para crianças de Educação Infantil com TEA, com base no uso do programa de adaptação de leitura Recall (Reading to Engage Children with Autism in Language and Learning/ Leitura para Engajar Crianças com Autismo na Linguagem e Aprendizagem) (WHALON; DELANO; HANLINE, 2015).

\section{A contação de histórias para crianças autistas}

A Educação Infantil passou a ser "obrigatória para as crianças de quatro e cinco anos apenas com a Emenda Constitucional n. ${ }^{\circ}$ 59/200926, que determina a obrigatoriedade da Educação Básica dos quatro aos 17 anos" (BRASIL, 2016, p. 34). Essa extensão de obrigatoriedade foi "incluida na LDB em 2013, consagrando plenamente a obrigatoriedade de matrícula de todas as crianças de quatro e cinco anos em instituições de Educação Infantil" (BRASIL, 2016, p. 34).

A Lei de Diretrizes e Bases da Educação Nacional (LDB), n. ${ }^{\circ}$ 9.394, e a inclusão da Educação Infantil na Base Nacional Comum Curricular (BNCC)
(BRASIL, 2018) foram, pois, um passo importante nesse processo histórico de integração da Educação Infantil ao conjunto da Educação Básica. Assim como possibilitado que as crianças com Transtorno do Espectro Autista (TEA) chegassem mais cedo aos bancos escolares. O autismo, cabe explicitar, foi definido, pela National Autistic Society como uma deficiência vitalícia do desenvolvimento que afeta os processos de comunicação e de relacionamento do sujeito com outra pessoa.

As alterações no desenvolvimento da criança com TEA manifestam-se já nos primeiros anos de vida e podem aparecer associadas a alterações neurológicas ou a comorbidades. A intensidade e a gravidade dos déficits na comunicação e no desenvolvimento da linguagem do autista, que caracterizam o transtorno, variam desde a ausência da fala até a fala hiperformal (WING, 1998). No caso da ausência da comunicação verbal, há uma falta de intercâmbios corporais expressivos, e, quando há comunicação verbal, há carência nos intercâmbios da conversação. Isso leva, conforme Hobson (1993), a uma sensação de privação de contato afetivo com o autista. Além disso, a forma como a pessoa com autismo se expressa, a fim de comunicar suas necessidades e seus desejos, normalmente não é, segundo Bosa (2002), imediatamente compreendida. Em algumas situações, por exemplo, a expressão do olhar dos autistas pode não ser compreendida por seu interlocutor ou ser compreendida de forma inadequada, por estabelecer um vínculo superficial, sem fixar a atenção por muito tempo, ou ainda, "porque não sabem a função comunicativa do olhar para compartilhar experiências com as pessoas" (BOSA, 2002, p. 35).

A partir do Manual de Diagnóstico Estatístico de Transtornos Mentais - DSM-5 - (APA, 2014), determinou-se o uso do termo Transtorno do Espectro Autista (TEA), que, em consonância com a Classificação Internacional de Doenças (CID-11), estabelece três categorias de autismo: leve, moderado e severo. Essa classificação constitui uma referência ao universo do autismo e está relacionada ao nível de dependência ou necessidade de suporte. 
O nivel de autismo é considerado leve quando a pessoa com esse diagnóstico consegue fazer as mesmas coisas que as pessoas sem esse diagnóstico fazem, mas possui dificuldades de comunicação e/ou interação social, mantém pouco ou nenhum contato visual com seu interlocutor, não aceita regras, tem dificuldades para modificar alguma coisa em sua rotina e apresenta estereotipias e repetições, sinais que, em alguns casos, podem ser bem sutis e, por isso, dificultar o diagnóstico precoce. O grau é considerado moderado quando o autista apresenta características intermediárias de independência, entre o leve e o severo. A pessoa com autismo moderado pode, em alguns casos, não desenvolver a fala. Já o sujeito com grau de autismo severo necessita de auxilio de cuidadores para realizar atividades simples, como tomar banho e escovar os dentes. Além disso, em algumas situações, pode se autoagredir.

Fernandes et al. (2009) ressaltam que 35\% a 45\% das crianças com autismo não chegam a desenvolver uma linguagem funcional e comunicativa. Isso não se deve à incapacidade de pronunciar palavras ou de construir sentenças, mas a aspectos semânticos da linguagem, da compreensão dos significados das palavras e de sua utilização social. É característica linguística comum dessas crianças a inversão do uso de pronomes pessoais, como, por exemplo, referirem-se a si próprias usando o "você" e, aos outros, usando "eu". Outra característica importante em $85 \%$ dos sujeitos com autismo que desenvolvem a fala é a ecolalia - a repetição do enunciado pode acontecer logo após a enunciação, assim como horas ou dias depois (SCHULER; PRIZANT, 1989). A tentativa de comunicação do autista também se dá pelo gesto de apontar, estudado por Goodhart e Baron-Cohen (1993), o qual pode ocorrer em situações não sociais e não somente como gesto protodeclarativo, identificado na atenção compartilhada.

Salienta-se que a inserção e a permanência dos alunos com TEA nas escolas regulares é amparada desde a Lei n. ${ }^{\circ}$ 12.764, de 27 de dezembro de 2012 (Lei Berenice Piana), que instituiu a Política Nacional de Proteção dos Direitos da Pessoa com Transtorno do Espectro Autista, e sofreu complementação pela Lei n. ${ }^{0}$ 13.977, de 8 de janeiro de 2020 (BRASIL, 2020). Desse modo, "a pessoa com transtorno do espectro autista é considerada pessoa com deficiência, para todos os efeitos legais", (BRASIL, 2012, p. 1). Assim sendo, os decretos relacionados aos direitos das pessoas com deficiências destinam-se também às pessoas com TEA, em todas as instâncias, sendo o ingresso na escola obrigatório, conforme o artigo $7^{\circ}$ (BRASIL, 2020).

Todavia, nem sempre os pais apresentam na escola, no ato na matrícula, o laudo com o número do CID (Código Internacional de Doença). Muitos omitem esse laudo, por diversas razões, o que dificulta ao professor realizar as adaptações necessárias, considerando-se as práticas pedagógicas inclusivas amparadas pela lei da inclusão.

Além disso, o que dificulta e restringe a aprendizagem e a escolarização de crianças com TEA é o fato de que podem ter, além de dificuldades de aprendizagem, problemas de conduta, de autorregulação, de percepção social e interação social, conforme o National Joint Committee on Learning Disabilities (1994). Embora essas características não sejam, por si próprias, a causa das dificuldades de aprendizagem, trazem empecilhos a esse processo, em especial, porque muitos professores não se sentem preparados para lidar com crianças com desenvolvimento atípico ou que não interajam com eles nem com os colegas, que não têm curiosidade pelo conhecimento, não participam das atividades propostas, e podem não demonstrar interesse pela leitura e pela escrita, conforme o grau do transtorno. Mas, apesar de tudo isso, conforme Oliveira (2015), tem sido realizados poucos estudos sobre práticas de leitura envolvendo pessoas com TEA no Brasil.

Quem convive com crianças com TEA, muitas vezes, depara-se com uma realidade bem desafiadora. Muitos pais e familiares informam que já percorreram um longo caminho buscando respostas para suas inquietações. Outros tentam descartar suas preocupações com base no fato de que todas as crianças são diferentes, que cada uma tem seu tempo. "Com esse discurso, o tempo vai passando, as famílias se desgastam, 
se confundem e, o que é mais preocupante, a criança com sinais de TEA vai crescendo sem ser bem compreendida e sem receber o atendimento de que necessita" (PORCIUNCULA, 2016, p. 30).

Nos últimos anos, tem-se percebido um número cada vez maior de crianças com TEA matriculadas em escolas regulares, principalmente nas de Educação Infantil, o que indica que a luta pela inclusão vem tendo bons resultados. Por isso, é indispensável conhecer mais sobre esses alunos e saber quais especificidades eles apresentam para o planejamento de ações que considerem não somente suas necessidades, mas, principalmente, as habilidades que possuem (CAMARGO; BOSA, 2012). Em função disso, faz-se necessário preparar/qualificar familiares e professores e, também, questionar e discutir as práticas pedagógicas atuais, desde a Educação Infantil, visando ao desenvolvimento dessas crianças.

De acordo com a Base Nacional Comum Curricular,

na Educação Infantil, é importante promover experiências nas quais as crianças possam falar e ouvir, potencializando sua participação na cultura oral, pois é na escuta de histórias, na participação em conversas, nas descrições, nas narrativas elaboradas individualmente ou em grupo e nas implicações com as múltiplas linguagens que a criança se constitui ativamente como sujeito singular e pertencente a um grupo social (BRASIL, 2018, p. 40).

A BNCC (2018) ressalta também a importância de as crianças pequenas ( 4 anos a 5 anos e 11 meses) participarem de situações de escuta de textos de diferentes gêneros textuais (poemas, fábulas, contos, receitas, quadrinhos, anúncios etc.). Nesse sentido, no Campo de Experiências, Escuta, Fala, Pensamento e Imaginação, o documento traz, entre outros, os seguintes objetivos:

(El03EFo6) Produzir suas próprias histórias orais e escritas (escrita espontânea), em situações com função social significativa.

(Elo3EF07) Levantar hipóteses sobre gêneros textuais veiculados em portadores conhecidos, recorrendo a estratégias de observação gráfica e/ou de leitura.

(El03EF08) Selecionar livros e textos de gêneros conhecidos para a leitura de um adulto e/ou para sua própria leitura (partindo de seu reper- tório sobre esses textos, como a recuperação pela memória, pela leitura das ilustrações etc.). (Elo3EFog) Levantar hipóteses em relação à linguagem escrita, realizando registros de palavras e textos, por meio de escrita espontânea (BRASIL, 2018, p. 48).

Atender esses objetivos é importante porque a infância é o momento propício não só para a inserção das crianças no mundo letrado, mas, também, para o desenvolvimento de seu imaginário, do mundo da fantasia, do faz de conta, o que contribui para a formação de leitores.

No que diz respeito às características de textos para crianças, Jesualdo (1938) já tinha referido que não devem ser abstratos, mas devem explorar a imaginação e o dramatismo. Além disso, ao selecionar uma obra para esse público, o professor precisa atentar também para a técnica narrativa e para a linguagem, que devem ser adequadas para esse público. Isso tudo, de acordo com o pesquisador, é "de suma importância para a degustação da obra" (JESUALDO, 1938, p. 51) pela criança.

Não são, pois, as letras, as sílabas e as palavras que encantam, em um primeiro momento, mas a história, cuja organização textual também contribui para isso. O estudioso alemão Bernhard Engelen (1995) destacou que as crianças da Educação Infantil e dos primeiros anos do Ensino Fundamental preferem frases curtas, voz ativa e enunciados expressos na ordem direta a frases com construções negativas. Também preferem orações relativas a atributos complexos, assim como orações principais ou com uma subordinada a orações mais complexas.

Desse modo, as fábulas, cujos textos, em geral, são curtos e de fácil compreensão, apresentam-se como possibilidade para o desenvolvimento e a formação do aluno/leitor nessa etapa da escolarização. Ademais, de acordo com Coelho (2000), é por meio dos contos de fadas, da utilização dos mitos, das próprias fábulas e do folclore que o leitor infantil se reconhece no contexto em que vive, compartilhando conquistas e se solidarizando com as dificuldades das personagens. 


\section{Do pré-leitor ao leitor: procedimentos metodológicos}

O papel da familia é essencial para a formação de um leitor. Entretanto, devido a diversos fatores, como, por exemplo, a vida agitada dos pais na contemporaneidade, essa responsabilidade é transferida unicamente para a escola. Menegassi (2005) reforça a ideia de que é na família que se inicia o processo de aprendizagem da leitura, embora seja tarefa primordial da escola alargar essa prática, oferecendo aos alunos, inicialmente, narrativas curtas, de fácil entendimento, para que eles se encantem e viagem pelo mundo da fantasia.

Com a contação de histórias, a criança vivencia experiências que estimulam o desenvolvimento de habilidades relacionadas à oralidade, à leitura e à escrita. Por isso, são importantes, no período de zero a seis anos, a qualidade e a frequência de experiências desafiadoras e lúdicas com vistas ao letramento e à exposição ao mundo letrado. $O$ potencial de desenvolvimento de determinadas habilidades por parte das crianças será "muito restrito se suas experiências acontecerem em ambientes pouco letrados ou se as experiências ocorrerem em condições precárias para o desenvolvimento do letramento emergente" (SEMEGHINI-SIQUEIRA, 2011, p. 157).

De acordo com Sulzby e Teale (1991), o letramento emergente é um conjunto de habilidades prévias de leitura e de escrita adquiridas pela criança no periodo compreendido entre o nascimento e a idade em que ela aprende a ler e a escrever de forma convencional. Para que ele seja desenvolvido, são necessárias práticas mediadas de leitura e de intervenções contextualizadas conforme as caracteristicas da criança.

Nesse contexto, foi desenvolvida a prática de leitura mediada para crianças pré-escolares autistas com nivel leve que aqui se apresenta, a qual teve como objetivo geral estimular o desenvolvimento do letramento emergente dessas crianças, utilizando como base o protocolo de ensino, que é baseado na Leitura Compartilhada, também denominada de Leitura Dialógica, que emprega estratégias interventivas de atenção compartilhada, a pausa intencional e os recursos visuais, conforme Walter e Nunes (2020). Nesse sentido, o Programa Recall (Reading to Engage Children with Autism in Language and Learning/ Leitura para Engajar Crianças com Autismo na Linguagem e Aprendizagem) tem como propósito desenvolver a compreensão leitora, em especifi$\mathrm{co}$, de crianças com TEA que apresentem dificuldades em reciprocidade social, comunicação e linguagem, atenção compartilhada e inferências (WHALON; DELANO; HANLINE, 2015).

Essa prática foi dividida em quatro momentos, tendo o primeiro sido dedicado à revisão bibliográfica sobre o TEA. A seguir, foram realizadas entrevistas com as professoras e com os familiares das crianças com TEA participantes da pesquisa para levantar dados sobre o perfil dos alunos. No terceiro momento, foi elaborado o produto deste estudo, o qual consiste em uma proposta de narração de histórias utilizando o programa de leitura Recall. E, para finalizar, foi feita a orientação para a prática de leitura para os mediadores (professoras e familiares).

O livro selecionado para o desenvolvimento desta proposta foi O Ratinho, o Morango Vermelho Maduro e o Grande Urso Esfomeado, de Wood e Wood (2000). A obra foi escolhida porque a narrativa é curta, o texto está escrito em caixa alta, facilitando o reconhecimento das letras por parte de crianças em processo de alfabetização, contempla os aspectos elencados por Engelen (1995) e encanta por sua história, a qual tem potencial para sensibilizar o leitor com as dificuldades enfrentadas pelas personagens, conforme indicam os estudos de Coelho (2000). Além disso, o livro fez parte do acervo do Programa Nacional do Livro Didático (PNLD), de 2000, e do Programa Leia para uma Criança, do Itaú, de 2012. Sendo assim, pode ser encontrado facilmente nas bibliotecas de muitas escolas e, até mesmo, em acervos pessoais.

Os participantes da pesquisa foram duas crianças com diagnóstico de TEA (nivel leve) de uma cidade do sul do Brasil, uma menina e um menino, nascidos em 2013 e 2014, respectivamente, as professoras das crianças (da Educação Infantil) e um familiar de cada uma das crianças. Antes de iniciar a investigação foi enviado, por intermédio 
da direção da escola na qual as crianças estavam matriculadas naquele ano (2018), aos pais e às professoras delas, um Termo de Consentimento Livre e Esclarecido (TCLE), o qual continha informações referentes ao projeto, tais como: objetivos da pesquisa, procedimento de coleta de dados e de utilização dos resultados para fins científicos, bem como a garantia de preservação da identidade dos participantes, para confirmar a anuência da participação na pesquisa.

Após a assinatura dos termos, confirmando a participação de todos no projeto, fez-se: a) entrevistas com os familiares das crianças participantes e com as professoras delas para estabelecer um perfil das crianças; b) depois, elaboraram-se dois roteiros de perguntas para mediar a leitura; c) por fim, foram fornecidas orientações às professoras e aos familiares para a realização de uma prática de leitura utilizando o Programa Recall.

\section{Apresentação e discussão da prática}

Para o desenvolvimento do projeto, realizou-se, em um primeiro momento, entrevistas com os familiares e com as professoras para coletar dados das crianças. Nessas entrevistas, os participantes foram questionados também sobre práticas de leitura.

As professoras informaram que seguidamente realizam leituras para os alunos. Para isso, as crianças se sentam em um círculo e ficam bem à vontade. Durante a leitura, as docentes costumam mostrar as gravuras dos livros para as crianças. Contudo, não costumam fazer perguntas ao longo da leitura ou narração da história, só fazem questionamentos ou atividades sobre a história lida ou narrada no final. As professoras, informaram, ainda, que não hábito realizar atividades de leitura especiais ou individuais para as crianças com TEA.

Os familiares das crianças com TEA, por sua vez, informaram que também costumam contar ou ler histórias para elas. E, assim como as professoras, não fazem perguntas ou pausas ao longo da leitura e tampouco conversam com as crianças sobre a história lida. No máximo, mostram as ilustrações do livro e deixam as crianças manuseá-lo, quando elas demonstram interesse para tal.

A partir dessas informações, elaborou-se uma proposta de leitura mediada do livro O Ratinho, - Morango Vermelho Maduro e o Grande Urso Esfomeado, de Wood e Wood (2000). Para tanto, foram elaborados dois roteiros de perguntas para a história, junto com os familiares e as professoras, para o desenvolvimento do letramento emergente das crianças, inspirado no Programa Recall. O primeiro roteiro contou com perguntas que começaram com as palavras interrogativas: "o que, quem, onde, quando, qual a cor, como, por que", objetivando a nomeação de substantivos e verbos. O segundo, teve estratégias do tipo "completar, completar fonológico, final aberto, evocar, inferências, identificação emocional", considerando uma interpelação por página (livro aberto).

Para cada pergunta do primeiro roteiro, foi confeccionado um cartão com um conjunto de três imagens, retiradas do Portal ARASAAC (Centro Aragonés de la Comunicación Aumentativa y Alternativa). Para cada pergunta, pressupõe-se apenas uma resposta correta. Exemplos desses cartões, criados para servirem como apoio visual para a narração da história, podem ser visualizados no Quadro 1. Para facilitar o manuseio, os cartões podem ser plastificados e encadernados ou fixados por velcro. 
Quadro 1 - Roteiro de perguntas 1

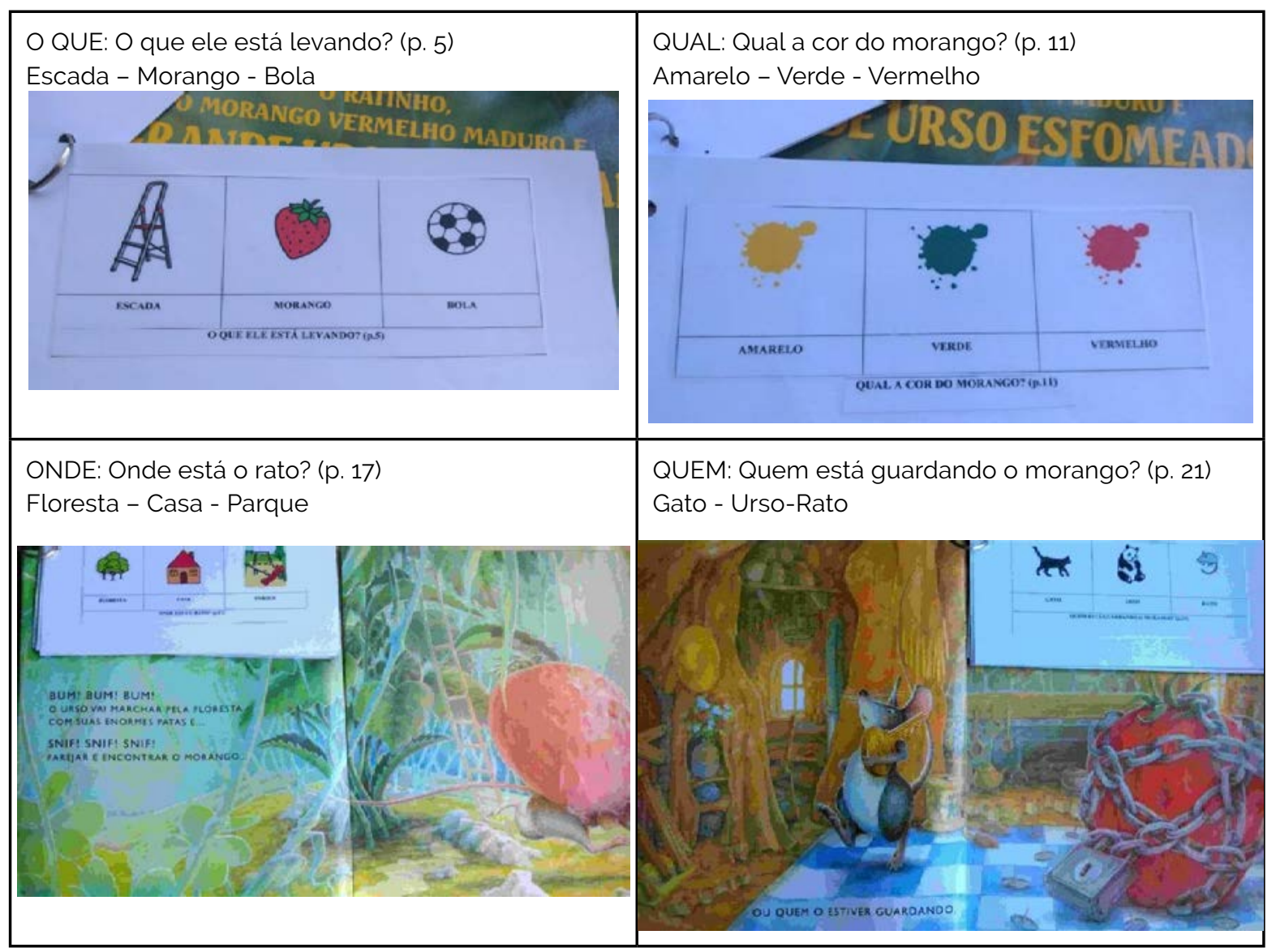

Fonte: elaborado pelas autoras.

Construidos os roteiros e o minilivro (cartões de respostas plastificados e encadernados), as professoras e os familiares foram orientados a ler para as crianças com TEA a história do livro O Ratinho, o Morango Vermelho Maduro e o Grande Urso Esfomeado, de Wood e Wood (2000), utilizando os roteiros de perguntas para mediar a leitura.

Solicitou-se que, no momento da leitura, fossem utilizados os roteiros de perguntas elaborados, uma pergunta para cada página do livro contada, para verificar se a criança estava compreendendo o que estava sendo lido. Se a criança não conseguisse responder ou se respondesse à pergunta de maneira equivocada, o mediador deveria utilizar um protocolo de leitura denominado estratégia Peep (Prompt, Evaluate, Expand, Praise), conforme Whalon et al. (2015), ou seja, um roteiro com ajudas visuais estruturadas. O protocolo, cujo nome vem do inglês, propõe que se forneçam dicas (Prompt), que se avalie a resposta dada (Evaluate), e, em seguida, se expanda a resposta (Expand), finalizando com um elogio (Praise). Foi pedido também aos pais e às professoras que filmassem a contação da história, para que pudesse ser feita uma análise posterior das interações.

Na escola, a história já tinha sido lida na hora do conto para a turma toda. Contudo, foi lida novamente, em um ambiente separado para as crianças com TEA, para que se utilizassem os roteiros de leitura elaborados e o minilivro como apoio visual. A análise das filmagens revelou que ambas as crianças responderam de forma satisfatória às atividades que as professoras realizaram. Elas mostraram-se interessadas pela história, responderam às perguntas e interagiram com as professoras ao longo da leitura. Verificaram-se, assim, avanços significativos, uma vez que, durante a hora do conto para a turma, essas crianças, geralmente ficam isoladas e desinteressadas. Em casa, quando os familiares contaram a história utilizando os roteiros de perguntas e o 
minilivro, as duas famílias também perceberam um envolvimento maior das crianças.

A análise dos momentos de narração da história revelou que as atividades desenvolvidas foram muito significativas para a compreensão da história por parte das crianças. Além disso, mostrou que elas se envolveram na narração e interagiram com os mediadores, o que pode ter contribuído para o desenvolvimento do letramento emergente delas e também para ampliar seu processo de comunicação.

Momentos como esses são muito importantes para crianças com TEA, eles podem influenciar positivamente no processo de alfabetização. Grande parte do sucesso escolar das crianças advém dos benefícios de um "ambiente familiar rico em eventos de letramento", afirma Terzi (1995, p. 93), porque eles motivam o envolvimento com a escrita e com a leitura de faz de conta, para o reconhecimento de palavras do cotidiano. Estímulos que podem e devem ser ampliados no ambiente escolar.

Ademais, por meio da leitura compartilhada, ou simplesmente manuseando livros, pode-se promover o desenvolvimento de habilidades, como: saber ouvir, interpretar, argumentar e posicionar-se diante de algum fato, as quais são muito importantes no processo de alfabetização.

\section{Considerações finais}

O presente estudo visou avaliar a importância de práticas compartilhadas de leitura para desenvolver o letramento emergente de crianças com TEA. Para tanto, analisou-se a narração compartilhada, com inspiração no programa Recall, da história do livro O Ratinho, o Morango Vermelho Maduro e o Grande Urso Esfomeado, de Wood e Wood (2000), para duas crianças autistas por seus familiares e por suas professoras.

A análise dos momentos de leitura compartilhada mostrou que a narração de histórias utilizando o programa Recall pode ser uma alternativa para trabalhar a leitura com crianças com TEA porque possibilita ao mediador realizar intervenções ao longo da contação da história para ampliar a compreensão da criança. Essas intervenções auxiliam a criança a manter a atenção na história, a organizar os elementos da narrativa, a lembrar dos fatos e a interpretar a história.

Sendo assim, pode-se inferir que a leitura compartilhada auxilia no desenvolvimento do letramento emergente de crianças com TEA. O letramento emergente auxilia no desenvolvimento de conhecimentos prévios e de habilidades relacionadas à leitura e à escrita que favorecem a aprendizagem formal futura da leitura e da escrita no Ensino Fundamental. Desenvolver o letramento emergente é muito importante para crianças autistas, porque podem apresentar dificuldades e também atrasos no processo de aquisição da leitura e da escrita.

Por isso, é imprescindivel que os familiares de crianças com TEA façam leituras compartilhadas com seus filhos e que os professores dessas crianças desenvolvam práticas pedagógicas envolvendo a leitura desde a Educação Infantil. Fazer isso não é garantia de sucesso, mas poderá contribuir para o desenvolvimento da linguagem da criança e, também, para seu processo de comunicação e de interação social.

\section{Referências}

APA, American Psychistric Association. Manual Diagnóstico e Estatístico de Transtornos Mentais. DSM-5. 5. ed. Porto Alegre: Artmed. 2014.

ARASAAC. Portal Aragonés de la Comunicación Aumentativa y Alternativa. Disponivel em: http://www. arasaac.org/. Acesso em: 15 jun. 2019.

BOSA, Cleonice. Atenção compartilhada e identificação precoce do autismo. Psicologia: Reflexão e Crítica, Porto Alegre, v.15, p. 77-88, 2002. https://doi.org/10.1590/ S0102-79722002000100010

BRASIL. Lei Federal n 12.764/2012, de 27 de dezembro de 2012. Institui a Politica Nacional de Proteção dos Direitos da Pessoa com Transtorno do Espectro Autista; e altera o $\S 3^{\circ}$ do art. 98 da Lei no 8.112, de 11 de dezembro de 1990. Diário Oficial Idal República Federativa do Brasil. Brasília, DF, 2012.

BRASIL. Lei Federal $n^{\circ}$ 13.977/2020, de 8 de janeiro de 2020. Altera a Lei no 12.764, de 27 de dezembro de 2012 (Lei Berenice Piana), e a Lei $n^{\circ}$ 9.265, de 12 de fevereiro de 1996, para instituir a Carteira de Identificação da Pessoa com Transtorno do Espectro Autista (Ciptea), e dá outras providências. Diário Oficial da União. Brasília, 2020. Disponivel em: https://www.in.gov. br/web/dou/-/lei-n-13.977. Acesso em: 16 set. 2020. 
BRASIL. Politica Nacional de Educação Infantil: pelo direito das crianças de zero a seis anos à educação. Brasilia: MEC, SEB, 2016. Disponivel em: http://www. oei.es/quipu/brasil/pol_educ_infantil.pdf. Acesso em 15 de julho/2019.

BRASIL. Ministério da Educação. Base Nacional Comum Curricular (BNCC): educação é a Base. Brasilia, MEC/ CONSED/UNDIME, 2017. Acesso em: out. 2019.

CAMARGO, S. P. H.; BOSA, C. A.. Competência social, inclusão escolar e autismo: Revisão critica da literatura. Psicologia e Sociedade, Florianópolis, v. 21, n. 1, p. 65-74, 2012. https://doi.org/10.1590/S010271822009000100008

COELHO, Nelly Novaes. Literatura infantil: teoria, análise, didática. São Paulo: Moderna, 2000.

ENGELEN, B. Überlegungen und Untersuchungen zur Syntax im Kinderbuch. In: FEINE, A.; SOMMERFELD, K. E. (org.). Sprache und Stil in Texten für Junge Leser. Festschrift für Hans-Joachim Siebert zum 65. Geburtstag. Frankfurt am Main: Lang, 1995, p. 43-63.

FERNANDES, A. V. et al. Autismo. Instituto de Computação Universidade Estadual de Campinas. 2009. Disponivel em: www.ic.unicamp.br/ wainer/cursos/g06/ trabalhos/autismo.pdf. Acesso em: 15 abr. 2019.

HOBSON, P. Understanding persons: The role of affect. In: S. BA. RON-COHEN, H.; TAGER-FLUSBERG; D. J. COHEN (org.). Understanding other minds: Perspectives from autism. Oxford: Oxford Medical Publications, 1993. p. 205-227.

JESUALDO. La literatura infantil. Buenos Aires: Editorial Losada S.A., 1938.

MENEGASSI, J.R. (org). Leitura e ensino. Maringá: EDUEM, 2005. p. 15-44.

NATIONAL AUTISTIC SOCIETY. Disponivel em: http:// www.nas.org.uk/. Acesso em: 10 mar. 2019

NATIONAL JOINT COMMITTEE FOR LEARNING DISABILITIES. Collective perspectives on issues affecting learning disabilities: position papers and statements. Autin: PRO-ED, 1994.

OLIVEIRA. R.M. Intervenções para melhorar dificuldade especifica de compreensão leitora. In: MOUSINHO, R.; MENDONÇA ALVES, L; CAPELLINI, S. (org.). Dislexia: novos temas, novas perspectivas. Rio de Janeiro: Wak, 2015. p. 219-232. v. 3.

PEETERS, T. Autism: From Theoretical Understanding to Educational Intervention. Whurr Publishers, 1998.

PORCIUNCULA, Rosa Angela Lameiro. Investigação precoce do transtorno do espectro autista: sinais que alertam para a intervenção. In: ROTTA, Newra Tellechea; BRIDI FILHO, César Augusto; BRIDI, Fabiane Romano de Souza (org.). Neurologia e Aprendizagem: abordagem multidisciplinar. Porto Alegre: Artmed, 2016.

SCHULER, A.; PRIZANT, B. Echolalia. In: SCHOPLER, E.; MESIBOV, G. Communication problems in autism. New York: Plenum, 1989. p. 163-184.
SEMEGHINI-SIQUEIRA, I. Recursos Educacionais Apropriados para Recuperação Lúdica do Processo de Letramento Emergente. Revista Brasileira de Estudos Pedagógicos, Brasília, v. 92, n. 230, p. 148-165, 2011 https://doi.org/10.24109/2176-6681.rbep.92i230.563

SULZBY, E.; TEALE, W. Emergent Literacy. In: BARR, R.; KAMIL, M.; MOSENTHAL, P.B.; PEARSON, P.D. (ed.). Handbook of Reading Research New York: Longman, 1991. p. 727-757.

TERZI, Sylvia Bueno. A Construção da Leitura. Campinas: Pontes. 1995

WHALON, K.; DELANO, M.; HANLINE, M.F. A Rationale and Strategy for Adapting Dialogic Reading for Children with Autism Spectrum Disorder: Recall, Preventing School Failure. Alternative Education for Children and Youth, v. 57, n. 2, p. 93-101, 2015. https://doi. org/10.1080/1045988X.2012.672347

WING, L. El Autismo en niños y adultos: Una guía para la familia. Buenos Aires: Paidós, 1998

WOOD, Audrey; WOOD, Don. O Ratinho, o Morango Vermelho Maduro, e o Grande Urso Esfomeado. Brinque Book, 2007

\section{Viviane Cristina de Mattos Battistello}

Doutoranda em Diversidade Cultural e Inclusão Social pela Universidade Feevale, Novo Hamburgo, RS, Brasil. Mestre em Letras pela Universidade Feevale, Novo Hamburgo, RS, Brasil. Professora e Psicopedagoga.

\section{Ana Teresinha Elicker}

Doutoranda em Diversidade Cultural e Inclusão Social pela Universidade Feevale, Novo Hamburgo, RS, Brasil. Mestre em Letras pela Universidade Feevale, Novo Hamburgo, RS, Brasil. Professora e Escritora.

\section{Lovani Volmer}

Doutora em Letras pela Universidade de Caxias do Sul (UCS), em Caxias do Sul, RS, Brasil; Professora da Universidade Feevale, em Novo Hamburgo, RS, Brasil.

\section{Rosemari Lorenz Martins}

Doutora em Linguistica pela Pontifícia Universidade Católica do Rio Grande do Sul (PUCRS), Porto Alegre, RS, Brasil. Professora da Universidade Feevale, em Novo Hamburgo, RS, Brasil

\section{Endereço para correspondência}

Viviane Cristina de Mattos Battistello

Universidade Feevale

ERS-239,2755, Prédio Lilás, $2^{\circ}$ andar

93525-075

Novo Hamburgo, RS, Brasil 